\title{
Treatment of the Distal Biceps Brachii Tendon Rupture Using the Three Mini-Incisions Technique: Evaluation through MEPS and DASH
}

\author{
José Antonio Galbiatti ${ }^{1 *}$, Luís Felipe Haber Figueiredo e Silva ${ }^{1}$, Gabriel Rodrigues dos Santos Milhomens ${ }^{1}$, \\ Fernando Marega Imamura ${ }^{2}$, Carlos Henrique Bertoni Reis ${ }^{2}$ and Marilia Gabriela Palacio Galbiatti²
}

${ }^{1}$ Faculdade de Medicina de Marília, Marília, São Paulo, Brazil

${ }^{2}$ Universidade de Marília, Marília, São Paulo, Brazil

Submission: July 03, 2019; Published: July 16, 2019

*Corresponding author: José Antonio Galbiatti, Rua Oswaldo Florindo Coelho, 80 (Zip code: 17525-120), Marília, São Paulo, Brazil

\begin{abstract}
Background: The distal biceps brachii tendon rupture is a rather uncommon injury. The proper procedure to be followed is an early surgical treatment. This study aims to describe the surgical technique of three mini-incisions, as well as evaluating the treatment results.

Materials and Methods: Retrospective study of ten patients who underwent surgery using the three mini-incisions technique due to distal biceps brachii tendon rupture.

Results: The mean follow-up was 42.9 months. In Mayo Elbow Performance Score (MEPS), nine patients' results were considered excellent (100 points). There was only one patient whose result in MEPS was considered good (85 points). Taking Disabilities of Arm, Shoulder and Hand (DASH) questionnaire into consideration, an average of 0.88 was found. There were two patients who reportedly felt mild pain in the Visual Analogue Scale (VAS). All patients expressed satisfaction with the treatment received. Movement amplitude and biceps brachii circumference did not demonstrate significant alterations when compared with the unaffected arm. There were neither complications nor clinically important late postoperative radiographic alterations among the ten patients who underwent evaluation.
\end{abstract}

Discussion: The three mini-incisions surgical technique associated with Bunnell suture and transosseus fixation has been proved adequate safe and reproducible for the treatment of distal biceps brachii tendon rupture and has presented satisfactory results in MEPS and DASH questionnaires.

Keywords: Elbow; Rupture; Tendons

\section{Introduction}

Distal biceps tendon ruptures are uncommon injuries, accounting for just 3\% of cases of biceps ruptures. In $96 \%$ of patients, an impairment of the long head occurs, and in $1 \%$ of the short head [1-9], proximally on the shoulder. It typically affects the dominant limb of middle-aged men, between 30 and 60 years of age [4,5,10-16]. In 1843, Starks apud Quach et al. [14] pioneered the description of the injury and in 1897, Johnson [17] was responsible for the first surgical correction. The prevalence is of approximately 1.2 cases/100 000 inhabitants, but it has increased with the current growing practice of sports activities. Known risk factors include smoking and the use of anabolic steroids [7-10,18-20]. Although not yet fully understood, the pathogenesis is attributed to the degeneration, hypovascularization and friction of the tendon [1,3,14-16,21]. There is evidence that the degeneration arises from the inflammation of the deep radial bursa, and that the friction is explained by bone irregularities in the radial tuberosity $[15,18]$.

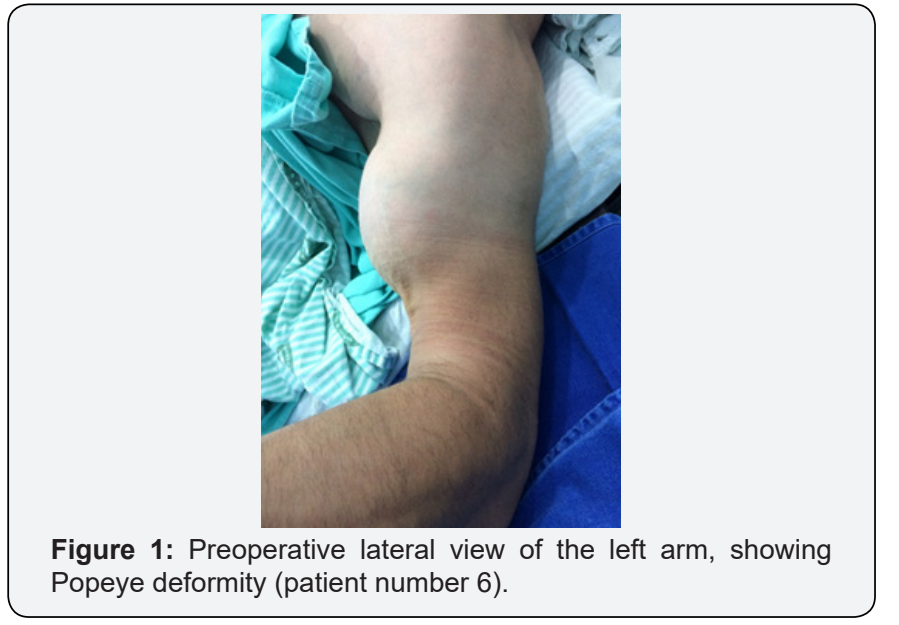

The most common injury mechanism is an eccentric muscle contraction against resistance with the elbow flexed at $90^{\circ}$ while the forearm is supinated $[6,10,11,16,22]$. Generally, the 
patient will report an audible crack in the elbow region. The clinical picture includes pain, edema and ecchymosis in the antecubital fossa, palpable defects in the distal tendon trajectory with alteration of the relief of the arm, decreased strength of supination of the forearm and elbow flexion. Positive results in the hook test and biceps squeeze test reinforce the diagnosis. In cases of complete rupture, a proximal muscle retraction occurs, responsible for the Popeye deformity [1-10,18-23] (Figure 1). The rupture is considered chronic after 4 weeks of the injury $[1,4,14]$.

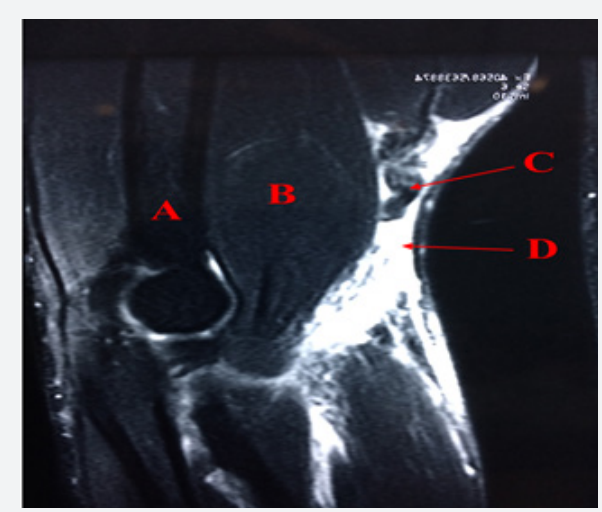

Figure 2: Preoperative magnetic resonance imaging, used for diagnostic confirmation and surgical planning (patient number 6). A: distal humerus. B: brachialis muscle. C: retracted tendon stump which was deinserted from the tuberosity of the radius by pulling out. D: hematoma located in the tunnel associated with the trajectory left by the distal tendon of the biceps brachii.

The imaging tests used to confirm the diagnosis include ultrasound and magnetic resonance imaging, the latter being considered the gold standard for definitive diagnosis and surgical planning (Figure 2). In addition, the exams assist in the investigation of associated lesions, the degree of retraction of Materials and Methods

Table 1: Serial number, initials, gender, age, affected arm, time elapsed between injury and surgical procedure, surgery date and follow-up time.

\begin{tabular}{|c|c|c|c|c|c|c|}
\hline Initials & Gender & Age & Affected Arm & $\begin{array}{c}\text { Time elapsed between injury and surgical } \\
\text { procedure (days) }\end{array}$ & Surgery Date & $\begin{array}{l}\text { Follow-up time } \\
\text { (months) }\end{array}$ \\
\hline EGS & M & 38 & non-dominant & 24 & Oct-10 & 94 \\
\hline PCCS & M & 48 & dominant & 7 & Apr-11 & 88 \\
\hline MLN & M & 47 & dominant & 1 & Sep-13 & 60 \\
\hline ALS & M & 40 & dominant & 13 & Dec-14 & 58 \\
\hline RBA & M & 43 & dominant & 8 & Oct-15 & 46 \\
\hline JRSR & M & 47 & non-dominant & 14 & May-16 & 27 \\
\hline MSSP & M & 49 & dominant & 10 & Aug-16 & 24 \\
\hline JJRB & M & 39 & non-dominant & 4 & Mar-17 & 15 \\
\hline $\mathrm{RBC}$ & M & 55 & non-dominant & 34 & Aug-18 & 10 \\
\hline DEMB & $\mathrm{M}$ & 42 & non-dominant & 3 & Nov-18 & 7 \\
\hline
\end{tabular}

A retrospective assessment of ten patients operated on between October 2010 and November 2018 was performed. The inclusion criteria were: patients with a diagnosis of acute complete rupture of the distal biceps brachii tendon,

surgically treated through the three mini-incisions technique. The injuries were diagnosed based on the clinical history and physical examination (Popeye deformity, palpation of the path of the biceps tendon and Hook test), confirmed by MRI 
and/or ultrasound exam. A chronologically ordered number was assigned to the patients based on the date of the surgical treatment (Table 1).

All patients were male and of Caucasian ethnicity. The mean age was 44.8 (ranging from 38 to 55). Two patients were using anabolic steroids (patients number 2 and 5), one was a smoker (patient number 1) and all practiced sports activities at the time of the injury. In our study, both dominant and non-dominant limbs were equally affected. The mean follow-up time was 42.9 months (ranging from 7 to 94). The patients were operated in the supine position with the upper limb abducted at $90^{\circ}$ and supported on a narrow table under locoregional anesthesia. We performed active exsanguination of the upper limb, using sterile elastic bands with the garrote at the root of the arm. The surgical technique in the treatment of distal biceps brachii tendon ruptures using three mini incisions is initiated with an incision of 3 to 4 centimeters $(\mathrm{cm})$ at 5 to $6 \mathrm{~cm}$ proximally from the elbow fold, in the region where the stump of the ruptured tendon is located. The region is occasionally swollen and painful on palpation, making it easier to plan for its location.

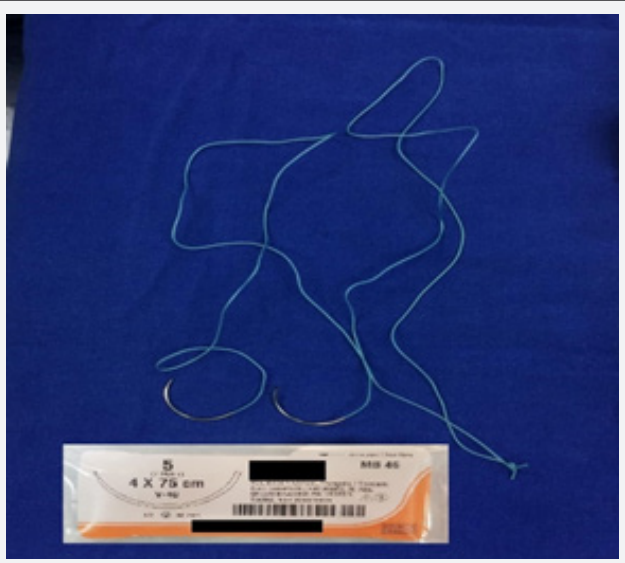

A

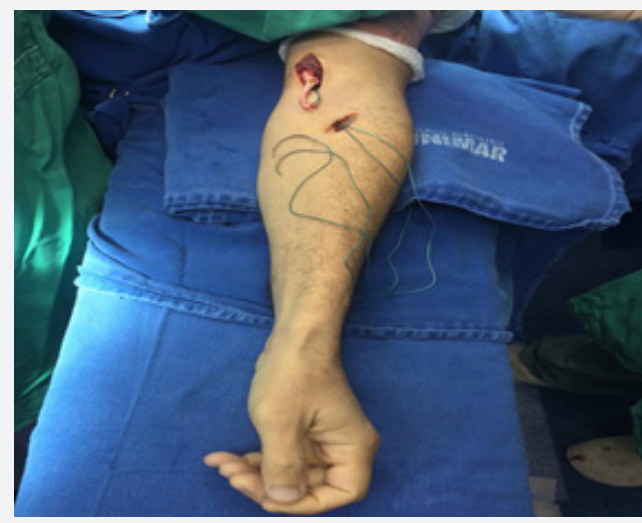

C

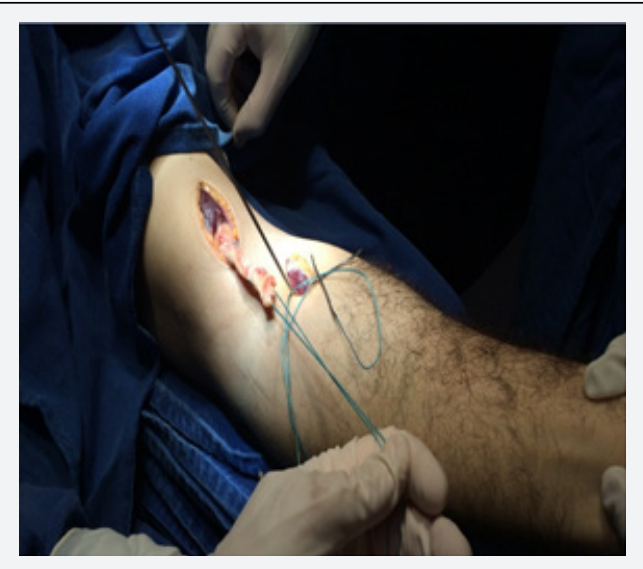

B

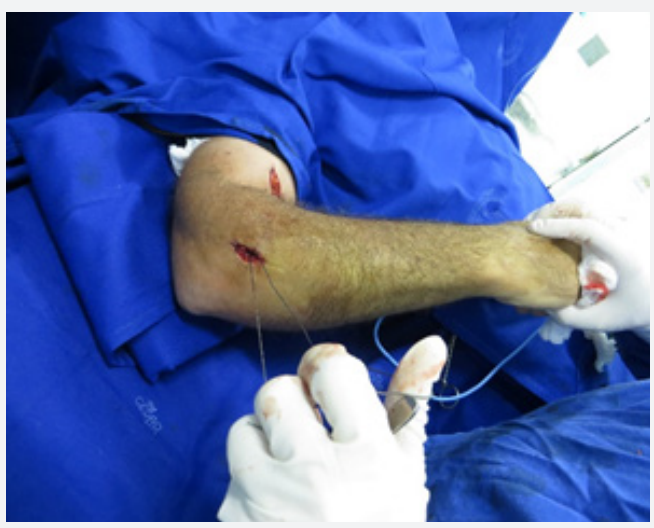

$D$

Figure 3: Perioperative pictures showing the surgical steps in the three mini-incisions technique. 3A: twisted 5.0 R polyester threads and a $\mathrm{V}-40,4 \times 75 \mathrm{~cm}$ needle. 3B: Bunnell suture in the biceps tendon with distal traction using rectified needles. 3C: externalization of the tendon through the proximal incision, performed after Bunnell suture. The threads are then passed through the distal incision. 3D: posterolateral view of the elbow at $90^{\circ}$ showing the third incision through which the threads were exteriorized for the transosseous fixation.

The subcutaneous tissue and thin brachial fascia are then opened, allowing access to the stump of the tendon, which was deinserted from the tuberosity of the radius by pulling out. We detach the tendon and exteriorize it through the small incision. Holding it with gauzes moistened in physiological serum at $0.9 \%$, an intense traction is performed on it in the distal direction in order to minimize the retraction related to the contraction of the biceps muscle. A resection of 0.3 to $0.5 \mathrm{~cm}$ of the distal portion of the tendon should be performed, transforming the stump in a vitalized sinewy area. Two twisted $5.0 \mathrm{R}$ polyester threads and a V-40, 4x75 cm needle (Figure $3 \mathrm{~A}$ ) were prepared, in which a junction knot was made, transforming them into a single thread with two needles. We reach the posterior portion of the brachial biceps muscle in its muscle-tendon transition (region that will remain in contact with the brachialis muscle) and then we initiate a Bunnell suture, with the needles in opposite directions, making each thread emerge in the distal portion of the tendon. We emphasize that the complete externalization of the tendon enables the execution of the Bunnell suture with ideal technical quality, allowing three to four passes increasing the strength of the tendon suture. The needles are then rectified using two needle holders, thus keeping the tendon ready for sequence of the surgical technique (Figure 3B).

By digit-palpation through the proximal incision, the tunnel associated with the trajectory left by the distal tendon of the biceps brachii is located, thus facilitating the planning of the 
second skin incision, located, on average, at 3 to $4 \mathrm{~cm}$ distally to the elbow fold. Through this deeper incision, the region of the radial tuberosity is projected, where the tendon was detached from. The dissection of this area should be done carefully, given the proximity of the superficial veins of the elbow, which must be retracted. In the divulsion of the Lacertus fibrosus, it is necessary to avoid injury to the cutaneous portion of the muscular-cutaneous nerve, also called the lateral cutaneous nerve of the forearm, since the neuropraxia of this nerve is the main postoperative complication in the treatment of distal biceps ruptures $[13,14]$. We use delicate and deep Langenbeck retractors to remove deep noble structures from the region, such as the median nerve and arteries and deep veins of the forearm.

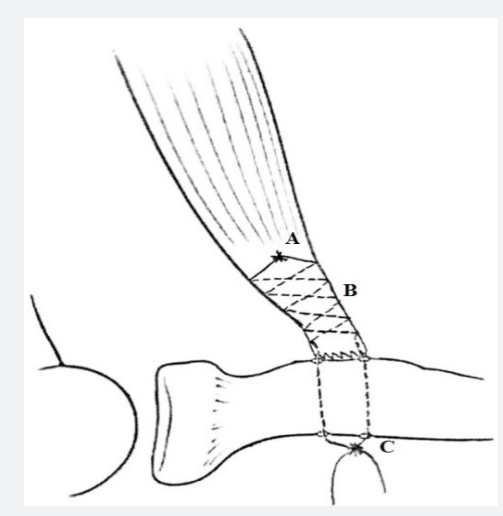

Figure 4: Illustration of lateral view of the elbow showing our transosseous fixation technique. A: knot made in the posterior portion of the brachial biceps muscle in its muscle-tendon transition. B: Bunnell suture with distal tendon externalization. C: knot made in the posterior portion of the radius after transosseous fixation in the radial tuberosity.

With the forearm in supination, we access the tuberosity of the radius, cleaning the periosteum with a spatula or rugine. Subsequently, two holes are made under direct vision in the radial tuberosity, about $0.5 \mathrm{~cm}$ apart - using a 2.0 milimeters $(\mathrm{mm})$ Kirschner wire -, trying to keep the forearm in supination at this moment (Figure 3C). We use Kelly tweezers introduced through the distal incision until the proximal incision to bring the already prepared tendon over the wire. At this time, we use a needle holder to insert the bottom (non-piercing) part of the needles into each of the previously prepared holes in the tuberosity of the radius. After palpating the forearm, the needles' exit area is located, where the third incision will be made (Figure

Results

Table 2: Serial number, MEPS, DASH, VAS, biceps brachii circumference at rest and under contraction and range of motion in flexoextension and pronosupination (affected arm / unaffected arm).

\begin{tabular}{|c|c|c|c|c|c|c|c|}
\hline $\begin{array}{c}\text { Serial } \\
\text { num- } \\
\text { ber }\end{array}$ & MEPS & DASH & VAS & $\begin{array}{c}\text { Greatest circumference of } \\
\text { the arm at rest (affected } \\
\text { arm/unaffected arm) (cm) }\end{array}$ & $\begin{array}{c}\text { Greatest circumference of } \\
\text { the arm under contraction } \\
\text { (affected arm/unaffected } \\
\text { arm) (cm) }\end{array}$ & $\begin{array}{c}\text { Range of motion } \\
\text { in flexoextension } \\
\text { (affected arm/ } \\
\text { unaffected arm) }(\underline{\mathbf{o}})\end{array}$ & $\begin{array}{c}\text { Range of motion in } \\
\text { pronosupination } \\
\text { (affected arm/ } \\
\text { unaffected arm) }(\mathbf{o} \text { ) }\end{array}$ \\
\hline 1 & 100 & 0.83 & 0 & $34 / 32,5$ & $37 / 39,5$ & $130-0 / 130-0$ \\
\hline 2 & 100 & 0 & 0 & $34 / 33$ & $38,5 / 38,5$ & $130-0 / 140-0$ \\
\hline 3 & 100 & 0 & 0 & $30,5 / 34$ & $34 / 35,5$ & $135-0 / 140--10$ & $90-90 / 90-90$ \\
\hline
\end{tabular}

3D). At this time, it is important to perform a divulsion of the musculature between the emergent area of the two needles / wires, since branches of the posterior interosseous nerve cross in this region and, under direct vision, one should avoid that it interposes itself to the wires. Subsequently, the wires are pulled with the elbow in supination and at a $90^{\circ}$ flexion. Knots are then made, and a digit-palpation evaluation of the tendon contact in the tuberosity of the radius is performed (Figure 4). Finally, a stability test of the tendon reinsertion, hemostasis, a skin suture and the development of an axilopalmar plaster splint is performed.

In the postoperative period, simple weekly dressings are applied and passive movements of flexoextension and partial pronosupination of the elbow are performed, with the arm supported on a stretcher. Between 18 and 25 days, the plaster is removed and replaced by a Velpeau-type fabric bracing, which should also be used when sleeping. At this point, the patient is allowed to perform active elbow flexion and pronosupination movements three to four times a day with the upper limb resting on a table in order to minimize the effect of gravity. In four to six weeks, on average, the patient is released from immobilization. The patients were evaluated based on a protocol previously developed by the authors. In the anamnesis, the presence of pain was investigated through the Visual Analogue Scale (VAS) and the function of the previously affected limb through the Mayo Elbow Performance Score (MEPS) and Disabilities of the Arm, Shoulder and Hand (DASH) questionnaires. The patients were questioned regarding the improvement of symptoms after surgery and the degree of satisfaction in relation to the applied treatment, defining it as satisfactory or unsatisfactory. In the physical examination, the region of greatest circumference of the arm at rest and under contraction was measured, in addition to checking the amplitude of movement in flexoextension and pronosupination with the use of a goniometer. The examinations were performed bilaterally, which allowed a comparative analysis between the limbs. Photographs of all patients were taken during the evaluation. An x-ray of the elbow was requested in the late postoperative period in two incidences (anteroposterior and profile). All patients signed an Informed Consent Form (ICF) before the evaluation and were informed about the nature of the research. The study was submitted to the evaluation and approval of the Ethics in Research Committee of our institution under the number CAAE 90111918.9.0000.5413. 


\section{Orthopedics and Rheumatology Open Access Journal (OROAJ)}

\begin{tabular}{|c|c|c|c|c|c|c|c|}
\hline 4 & 100 & 0 & 0 & $38 / 38$ & $42 / 42$ & $135-0 / 135-0$ & $90-90 / 90-90$ \\
\hline 5 & 100 & 0 & 0 & $35 / 36,5$ & $40 / 41$ & $120-0 / 120-0$ & $85-80 / 90-80$ \\
\hline 6 & 100 & 6.66 & 3 & $33 / 33$ & $37,5 / 38$ & $135-0 / 135-0$ & $90-85 / 90-85$ \\
\hline 7 & 100 & 0 & 0 & $33,5 / 33$ & $36 / 35$ & $145-0 / 145-0$ & $90-85 / 90-85$ \\
\hline 8 & 100 & 0 & 0 & $37 / 36,5$ & $40 / 39$ & $130-0 / 120-0$ & $90-90 / 90-90$ \\
\hline 9 & 100 & 0 & 0 & $30 / 30$ & $34 / 35$ & $145-0 / 145-0$ & $90-90 / 90-90$ \\
\hline 10 & 85 & 1.31 & 3 & $33 / 36$ & $38 / 40$ & $145-0 / 145-0$ & $90-90 / 85-90$ \\
\hline
\end{tabular}

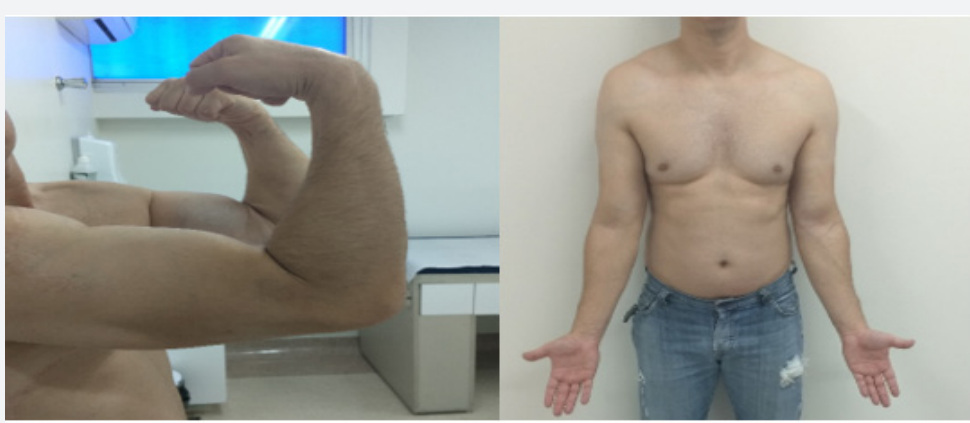

A

B

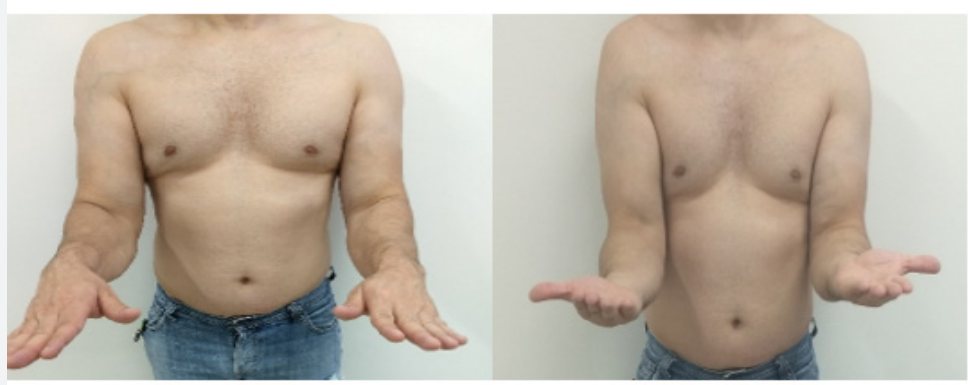

C

D

Figure 5: Postoperative pictures taken 15 months after surgery showing bilateral comparison of the range of motion in flexoextension and pronosupination (patient number 8). 5A: isometric contraction. 5B: extension. 5C: pronation. 5D: supination.

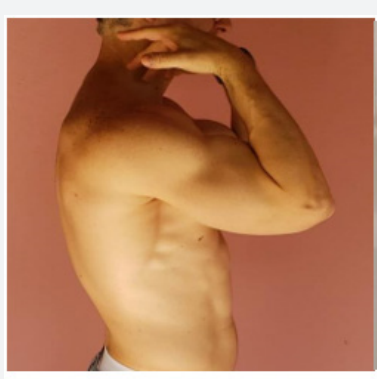

A

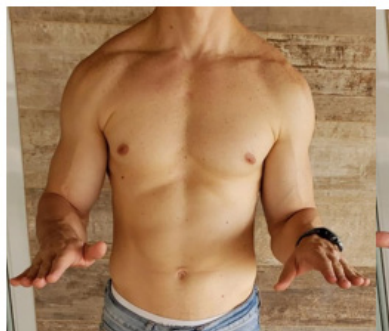

c

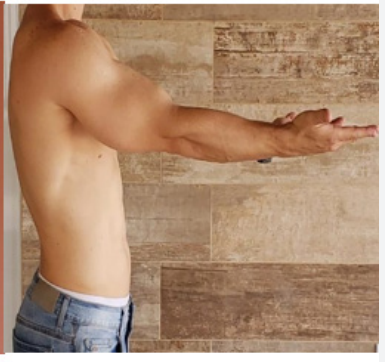

B

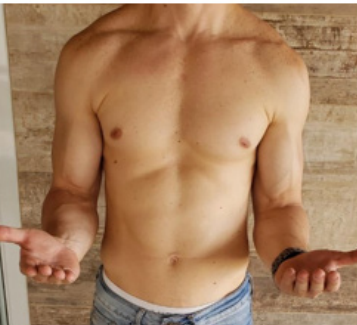

D

Figure 6: Postoperative pictures taken 58 months after surgery showing bilateral comparison of the range of motion in flexoextension and pronosupination (patient number 4). 6A: flexion. 6B: extension. 6C: pronation. 6D: supination. 
All ten patients declared themselves satisfied with the established treatment with regard to the degree of satisfaction after surgery. All patients reported functional recovery of the affected upper limb after the surgical treatment concerning the improvement of the symptoms. Eight scores of 0 and two scores of 3 were obtained with the application of the VAS. As for the MEPS, 100 points were obtained for nine patients. One patient scored 85 points. A mean of 0.88 (ranging from 0 to 6.66) was obtained for the DASH score. Table 2 shows the information regarding the VAS, MEPS and DASH results, as well as a bilateral comparison of the greatest circumference of the arm (at rest and under contraction) and the range of motion in flexoextension and pronosupination. Patients returned to their daily living activities without restriction six months after surgery. All had good functional results and did not present significant changes in the range of motion regarding flexoextension and pronosupination (Figures 5 \& 6). There were no postoperative complications. In the late radiographic evaluation, patient number 2 presented calcifications of the soft tissue anterior to the radial tuberosity and avulsion of the olecranon enthesophyte, which do not cause functional impairment (Figures $7 \& 8$ ).

\section{}

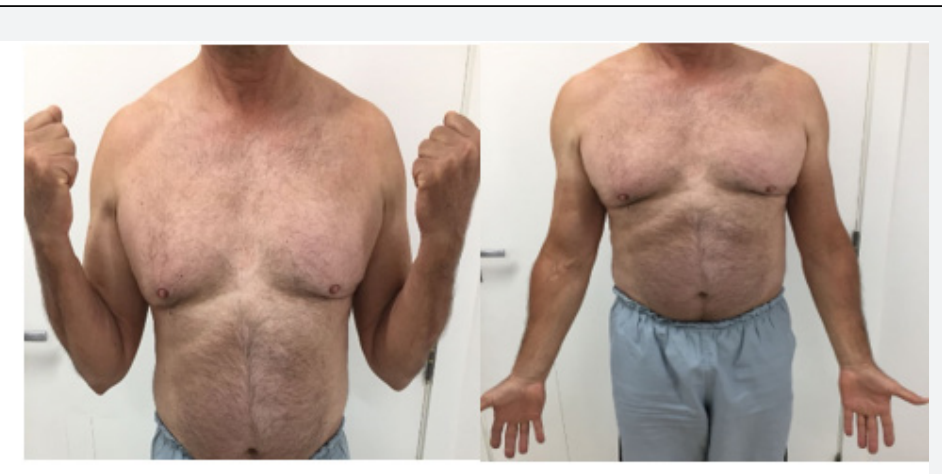

A

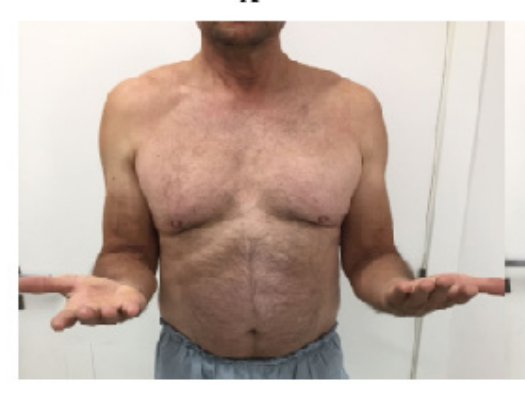

$c$
B

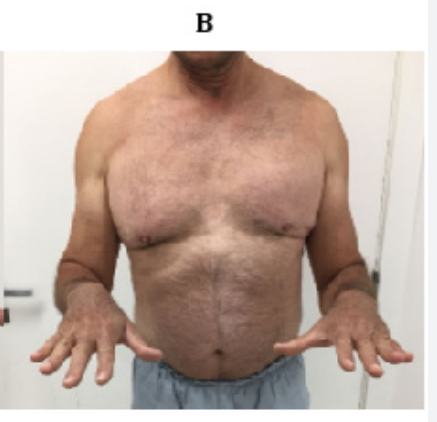

n

Figure 7: Postoperative pictures taken 88 months after surgery showing bilateral comparison of the range of motion in flexoextension and pronosupination (patient number 2). 7A: flexion. 7B: extension. 7C: pronation. 7D: supination.

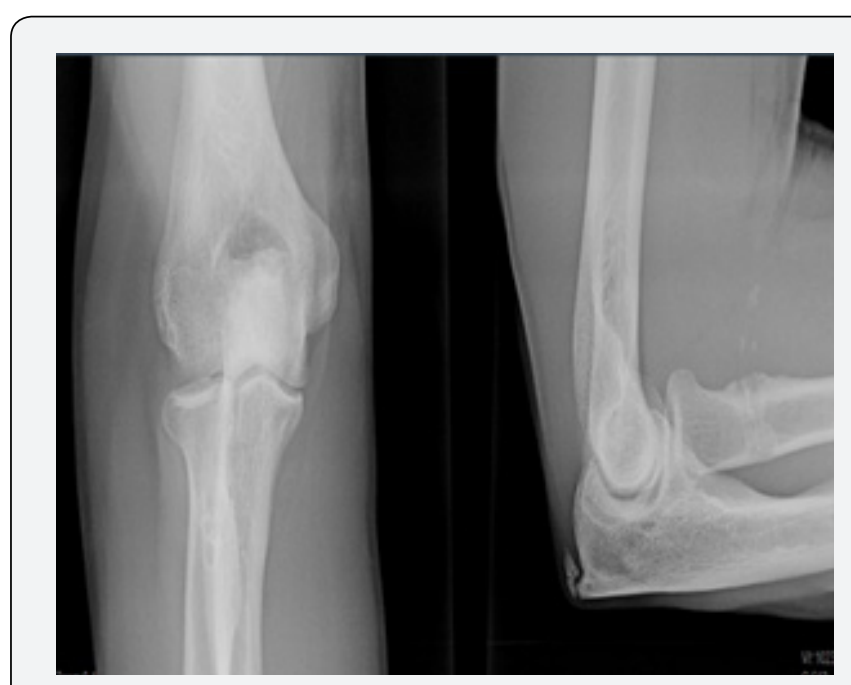

Figure 8: Late radiographic evaluation of right elbow (patient number 2) presenting bone tunnels in the radial tuberosity, calcifications of the soft tissue anterior to it, avulsion of the olecranon enthesophyte and preserved joint spaces.

\section{Discussion}

Distal biceps tendon ruptures are uncommon injuries, accounting for just $3 \%$ of cases of biceps ruptures. It mainly affects the dominant limb of middle-aged men [1-7]. The prevalence has increased in recent years due to the growing practice of sports activities [8-10,18-20]. The most common mechanism of injury is an eccentric muscular contraction against resistance with the elbow flexed at $90^{\circ}$ and the forearm supinated $[6,10,11,16,22]$. In our study, the mean age was consistent with the range predicted in the literature, corresponding to 44.8 years (with extremes of 38 and 55), as was the sex of the patients - all males. All the patients had an injury mechanism related to the practice of sports activities. Both dominant and non-dominant limbs were equally affected, each one in five cases $[4,5,10,11,16]$.

The usual clinical presentation includes pain, edema, ecchymosis, a palpable defect in the distal trajectory of the tendon, as well as decreased strength and range of motion. Classical findings include positive Hook test and biceps squeeze test, in 


\section{Orthopedics and Rheumatology Open Access Journal (OROAJ)}

addition to the Popeye deformity. Magnetic resonance imaging is considered the gold standard for diagnostic confirmation and surgical planning [1-10,18-22]. The recommended treatment is early surgical intervention, which is considered superior to conservative treatments. Ward et al. [3] advocate the use of conservative treatments only for the elderly and patients with low functional demand. Morrey et al. [24] showed that, compared to the surgical treatment, the conservative treatment results in a loss of $40 \%$ of the supination strength and $30 \%$ of the flexion force. The use of an adequate surgical technique and the time elapsed between the injury and the surgical procedure are the most important factors for the prevention of complications [23]. Kelly et al. [25] reinforce the importance of an early surgical intervention in order to obtain better results. In their studies, they found an increase from $22 \%$ to $41 \%$ in the rate of complications when surgery was performed 10 days after the injury. In this regard, our study had an average time between injury and surgery of 11.8 days, ranging from 1 to 34 , which also influenced the good results obtained.

This study uses a relatively small number of cases, as in other publications about the rupture of the distal biceps brachii, which is explained by its low incidence. No patient has been lost since the surgery so far. The results obtained using the three mini-incisions technique were satisfactory according to both subjective assessments - the residual pain scale (VAS), the degree of satisfaction with the established treatment and the preservation of the limb's functional capabilities, which is reflected in the results of the MEPS and DASH scales, which have been validated in the literature - and objective criteria, manifested through the absence of postoperative complications and a timely return to daily life activities. These data can be easily observed by evaluating the postoperative photographic documentation of the described patients.

Historically, surgical treatment began with the use of a single anterior access route, proposed by Henry apud Ward et al. [3]. Conversely, given its extensive exposure, several cases of radial, medial, ulnar and cutaneous-lateral forearm lesions as well as neuropraxia of the posterior interosseous nerve have been reported due to excessive cutaneous retraction [1-3,5,19,23]. To date, a high rate of complications is still documented in the literature, close to 25\% [15,20]. In 1961, Boyd \& Anderson [26] developed the two-incisions technique in an attempt to reduce dissection and the risk of injury of the neurovascular structures. Although this technique has favorable results, it may evolve negatively with heterotopic ossification, proximal radioulnar synostosis and a decreased range of motion [5,9,13-19,21]. In 1985, Morrey et al. [24] modified this technique in order to avoid subperiosteal ulnar exposure $[3,7,9,11,22]$. Even today, several approaches are used to reinsert the distal biceps. The continuous appearance of new techniques is explained by the attempt to recover the functional capacity of the affected limb while at the same time reducing the rate of postoperative complications. However, there is still no consensus regarding the superiority of any technique or method of fixation.
The authors chose to use a surgical approach with three mini-incisions. This technique requires materials that are available at most hospitals worldwide (pneumatic perforator, $2.0 \mathrm{~mm}$ Kirschner wires and two polyester threads) and it seeks to minimize surgical trauma and economic costs. In addition to these factors, the technique has great reproducibility and it ensures a satisfactory functional recovery of the affected limb in the postoperative period and better aesthetic results regarding skin scars.

Maciel et al. [8] conducted a study with 22 patients operated by single access and fixation with a suture anchor. The patients showed good functional results, as reflected by the VAS, MEPS, degree of satisfaction and Andrews-Carson scores, but the complication rate was $27.2 \%$, with neuropraxia of the lateral cutaneous nerve of the forearm as the main occurrence. Chavan et al. [27] performed a systematic review comparing the technique with single and two incisions, in which complication rates of $18 \%$ and $16 \%$ were obtained, respectively. These data reveal that both techniques still have considerable rates of complications.

We emphasize that the good results observed have a close association with the Bunnell suture technique, which is considered a modality with a high tensioning capability, enabling a satisfactory, direct coaptation between the distal biceps tendon stump and its origin in the radial tuberosity [28]. It is worth stating that the tendon externalization performed through the first incision, as described in the surgical technique, allows the Bunnell suture to be performed with multiple passes, which contributes to greater tension and stability. To date, our approach seems quite adequate, since no patient presented postoperative complications, functional deficits or new ruptures. We consider this to be relevant since this is a study with a relatively long follow-up, ranging from 7 to 94 months (mean of 42.9). All patients were able to return to the original sports practiced at the time of injury and reported satisfaction with the treatment. We obtained positive results on the MEPS and DASH scales, which have been scientifically validated as sensitive and responsive instruments that evaluate the function and symptomatology of the limb previously affected from the patient's own perspective, thus reaffirming the quality of the surgical technique.

\section{Conclusion}

The surgical approach with three mini incisions, performed by Bunnell suture and transosseous fixation, proved to be a lowcost and adequate technique both aesthetically and functionally for the treatment of distal biceps rupture, with satisfactory results in the MEPS and DASH questionnaires.

\section{References}

1. Thomas JR, Lawton JN (2017) Biceps and triceps ruptures in athletes. Hand Clin 33(1): 35-46.

2. Júnior JCG, Filho CDCC, Mello TFC, Vasconcelos RA, Zabeu JLA, et al. (2012) Lesão do bíceps distal: avaliação funcional e dinamometria dig- 
ital da sua reconstrução pela técnica da minidupla via de Mayo. Rev Bras Ortop 47(5): 581-587.

3. Ward JP, Shreve MC, Youm T, Strauss EJ (2014) Ruptures of the distal biceps tendon. Bull Hosp Jt Dis 72(1): 110-119.

4. Burnev M, Ganchev G, Penev P (2016) Distal biceps tendon rupture: a single-incision repair with endobutton. Scripta Scientifica Medica 48(3): 30-33.

5. Tat J, Hart A, Cota A, Alsheikh K, Behrends D, et al. (2018) Anatomic single-incision repair of distal biceps tendon ruptures using flexible reamers. Arthrosc Tech 7(2): e179-183.

6. Witkowski J, Królikowska A, Czamara A, Reichert P (2017) Retrospective evaluation of surgical anatomical repair of distal biceps brachii tendon rupture using suture anchor fixation. Med Sci Monit 23: 49614972.

7. Pascarelli L, Righi LCS, Bongiovanni RR, Imoto RS, Teodoro RL, et al. (2013) Resultados e técnica da reparação do tendão bicipital distal através de duas mini-incisões anteriores. Acta Ortop Bras 21(2): 76-79.

8. Maciel RA, Costa PS, Figueiredo EA, Belangero PS, Pochini AC, et al. (2017) Lesão do bíceps distal aguda: reparo por via única e fixação por âncora de sutura. Rev Bras Ortop 52(2): 148-153.

9. Miyazaki AM, Fregoneze M, Santos PD, Silva LA, Sella GV, et.al. (2014) Avaliação funcional dos pacientes com lesão da inserção distal do músculo bíceps braquial tratados cirurgicamente. Rev Bras Ortop 49(2): 129-133.

10. Haverstock J, Athwal GS, Grewal R (2015) Distal biceps injuries. Hand Clin 31: 631-640.

11. Kodde IF, Baerveldt RC, Mulder PGH, Eygendaal D, Bekerom MPJ (2016) Refixation techniques and approaches for distal biceps tendon ruptures: a systematic review of clinical studies. J Shoulder Elbow Surg 25: e29-e37.

12. Guglielmino C, Massimino P, Ioppolo F, Castorina S, Musumeci G, et al. (2016) Single and dual incision technique for acute distal biceps rupture: clinical and functional outcomes. Muscles Ligaments Tendons J 6(4): 453-460.

13. Panagopoulos A, Tatani I, Tsoumpos P, Ntourantonis D, Pantazis K, et al. (2016) Clinical outcomes and complications of cortical button distal biceps repair: a systematic review of the literature. J Sports Med (HindawiPublCorp). 2016: 3498403.

14. Quach T, Jazayeri R, Sherman OH, Rosen JE (2010) Distal biceps tendon injuries: current treatment options. Bull NYU Hosp Jt Dis 68(2): 103111.

This work is licensed under Creative Commons Attribution 4.0 License DOI: 10.19080/OROAJ.2019.14.555888
15. Vandenberghe M, Riet R (2016) Distal biceps ruptures: open and endoscopic techniques. Curr Rev Musculoskelet Med 9(2): 215-223.

16. Amin NH, Volpi A, Lynch TS, Patel RM, Cerynik DL, et al. (2016) Complications of distal biceps tendon repair: a meta-analysis of single-incision versus double-incision surgical technique. Orthop J Sports Med 4(10): 1-5.

17. Johnson $A B$ (1897) Avulsion of biceps tendon from the radius. New York M J 66: 261-262.

18. Stoll LE, Huang JI (2016) Surgical treatment of distal biceps ruptures. Orthop Clin N Am 47(1): 189-205.

19. Fletcher C (2017) Management of distal biceps tendon ruptures. Global Journal of Medical Research H 17(1): 12-18.

20. Hammarstedt JE, Savin DD, Goldberg BA (2017) Single-incision anatomic repair technique for distal biceps tendon rupture using tunneling device. Arthrosc Tech 6(4): e945-e950.

21. Freitas F, Ramos A, Luís NM, Correia AR, Oliveira M, et al. (2012) Rotura do tendão distal do bicípite braquial. Rev Port Ortop Traum 20(2): 243-248.

22. Medina GIS, Roselis DG, Sano M, Kikuta FK, Cruz MA, et al. (2010) Reparo da ruptura distal aguda do tendão do bíceps braquial com âncoras de sutura. Revista Ortopedia e Traumatologia Ilustrada 1(4): 135-141.

23. Dunphy TR, Hudson J, Batech M, Acevedo DC, Mirzayan R (2017) Surgical treatment of distal biceps ruptures: ananalysis of complications in 784 surgical repairs. AJSM 45(13): 3020-3029.

24. Morrey BF, Askew LJ, An KN, Dobyns JH (1985) Rupture of the distal tendon of the biceps brachii: a biomechanical study. J Bone Joint Surg Am 67(3): 414-417.

25. Kelly EW, Morrey BF, O’Driscoll SW (2000) Complications of repair of the distal biceps tendon with the modified two-incision technique. J Bone Joint Surg Am 82A: 1575-1581.

26. Boyd HB, Anderson LD (1961) A method for reinsertion of the distal biceps brachii tendon. J Bone Joint Surg Am 43: 1041-1043.

27. Chavan PR, Duquin TR, Bisson LJ (2008) Repair of the ruptured distal biceps tendon: a systematic review. Am J Sports Med 36(8): 16181624.

28. Jordan MC, Hoelscher-Doht S, Fehske K, Gilbert F, Jansen H, et al. (2015) Bunnell or cross-lock Bunnell suture for tendon repair? Defining the biomechanical role of suture pretension. J Orthop Surg Res 10(192): e1-e8.

\section{Your next submission with Juniper Publishers} will reach you the below assets

- Quality Editorial service

- Swift Peer Review

- Reprints availability

- E-prints Service

- Manuscript Podcast for convenient understanding

- Global attainment for your research

- Manuscript accessibility in different formats

( Pdf, E-pub, Full Text, Audio)

- Unceasing customer service

Track the below URL for one-step submission https://juniperpublishers.com/online-submission.php 